\title{
Trochanteric Fracture of a Congenital/ Developmental Dislocation of the Hip in an Elderly Woman: A Case Report
}

\author{
Kazuhiro Imai \\ Department of Orthopaedic Surgery, Mishuku Hospital, Tokyo, Japan. \\ Email: imaik-ort@umin.ac.jp
}

Received July 22 ${ }^{\text {nd }}$, 2011; revised August 25 ${ }^{\text {th }}$, 2011; accepted September $4^{\text {th }}, 2011$.

\begin{abstract}
An 87-year-old woman with a residual dislocated hip suffered a trochanteric fracture on the ipsilateral side. The fracture was treated by open reduction and internal fixation surgery with good results. To treat a proximal femoral fracture of the residual dislocated hip in an elderly patient, the patient's overall status, pre-fracture ability, hip joint configuration, and fracture pattern should be considered.
\end{abstract}

Keywords: Congenital/Developmental Dislocation of the Hip, Trochanteric Fracture, Elderly Woman

\section{Introduction}

Managing congenital/developmental dislocation of the hip (CDH) in adults presents many challenges. It is also difficult to manage a trochanteric fracture in a patient with $\mathrm{CDH}$. We present an elderly woman with a trochanteric fracture of a $\mathrm{CDH}$ who underwent open reduction and internal fixation surgery. We also describe the treatment options that allowed for restoration of the patient's pre-fracture status.

\section{Case Report}

An 87-year-old woman slipped and fell to the floor at home and was admitted urgently to our hospital with left hip pain and an inability to walk. The patient had a history of CDH and her pre-fracture activity level was double-crutch walking. She had used crutches since she was 42 years old. She had hypertension and was diagnosed with congestive heart failure when she was 86 years old. Her height was $147 \mathrm{~cm}$ and her weight was $46 \mathrm{~kg}$.

Radiographs showed a fracture at the left proximal femur (AO classification of trochanteric fractures type A3) and a residual dislocated hip on the ipsilateral side (Figure 1). The residual femoral neck was located in the gluteal muscles above the original acetabulum. The amount of subluxation was more than 100\% (Crowe type IV [1]). The left femoral head and the lesser trochanter were absent. The left femoral neck was short and the proximal femoral shaft was narrow. The right hip formed the secondary acetabulum above the original acetabulum. The right femoral neck was extremely short and the right femoral head was severely deformed.

At first, a nonsurgical approach was taken. The patient remained on bed rest for 3 weeks without traction. At 3 weeks, radiographs showed the displaced fracture and no bone formation (Figure 2).

The fracture was treated by open reduction and internal fixation surgery. A traction table and X-ray fluoroscopy were used. The displaced fracture was reduced with the left hip 10 degrees adducted. The proximal femur

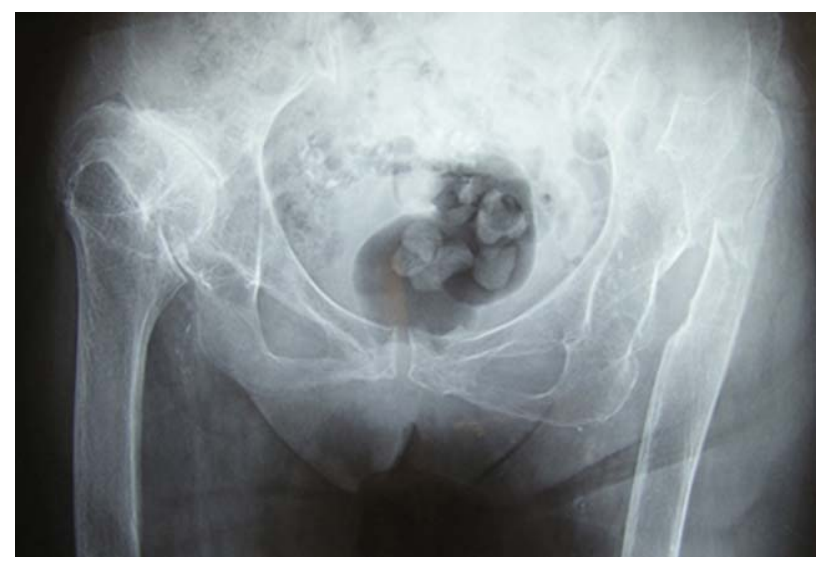

Figure 1. Radiograph of the pelvis on admission showing fracture at the proximal left femur and residual dislocated hip on the ipsilateral side. 
was explored through a lateral incision. A $50 \mathrm{~mm}$ lag screw was inserted into the proximal fragment and a 95degree DCS ${ }^{\circledR}$ plate (Synthes, West Chester, Pennsylvania, USA), stabilized by four cancellous screws and three cortical screws, was used (Figure 3).

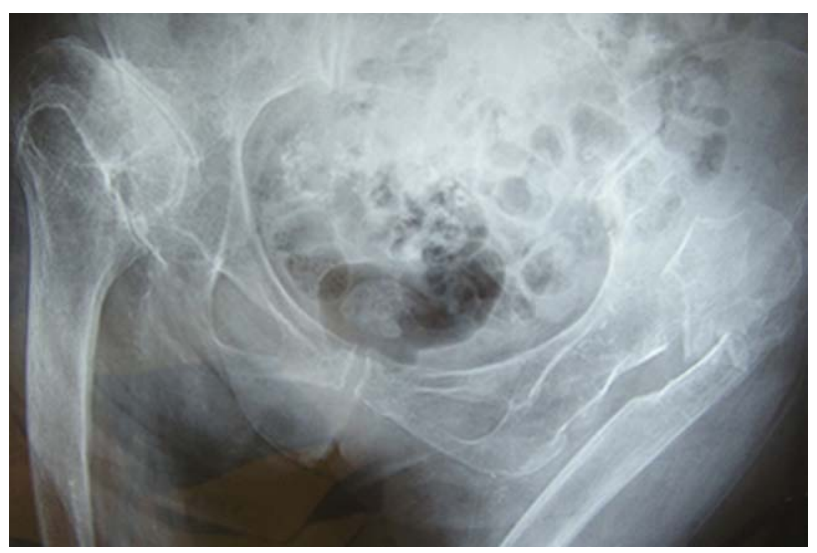

Figure 2. Radiograph 3 weeks after admission, showing the displaced fracture without bone formation.

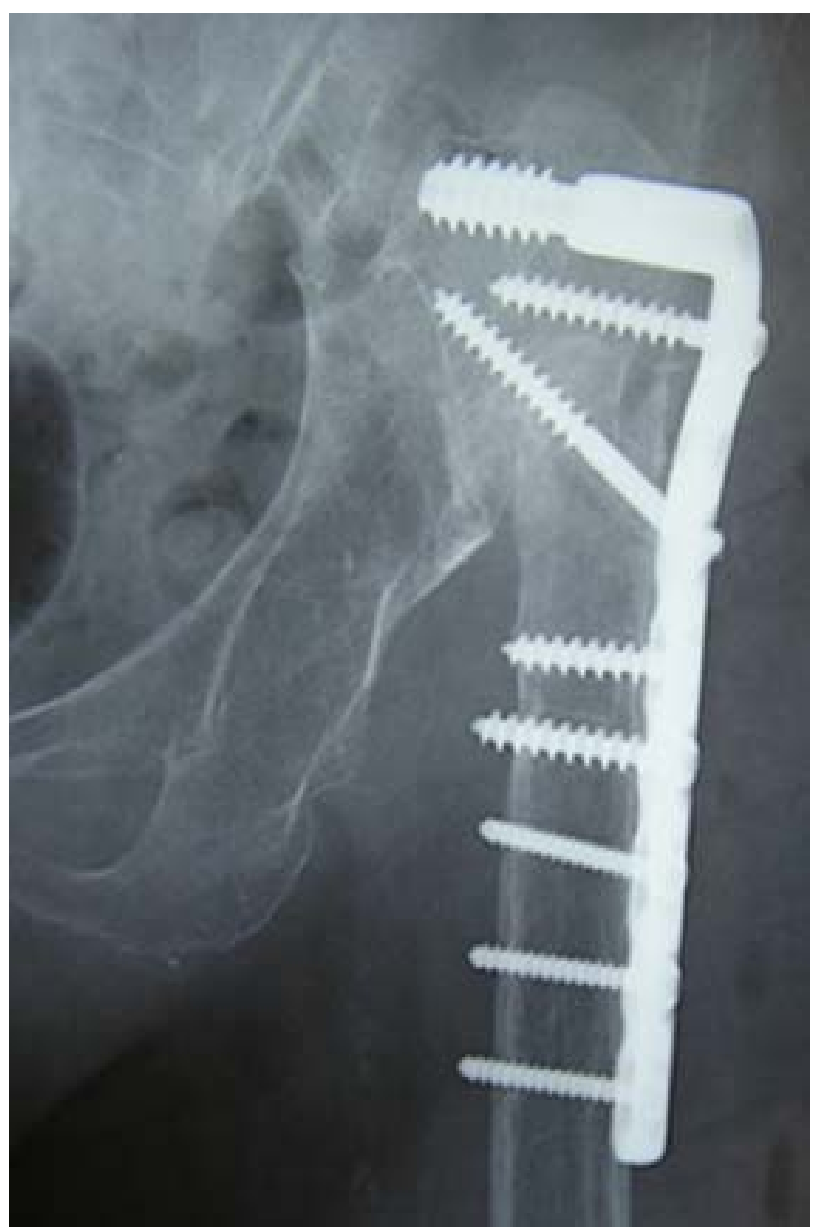

Figure 3. Postoperative radiograph of the left hip.
The patient remained on bed rest for 2 weeks without an external fixation and 2 weeks after surgery, she started sitting in a wheelchair. At 4 weeks, bone formation at the fracture site was noted and partial weight bearing was started. Full weight bearing was started 6 weeks postoperatively. She was able to walk 50 meters with doublecrutches 3 months postoperatively. She was able to walk indoors with double crutches 2 years postoperatively at the age of 89. Radiographs showed healed fracture (Figure 4). Consent for publication has been obtained from the patient and her daughter.

\section{Discussion}

Newborn and infant screening and prevention of CDH has been in place since the 1970s in Japan, and the presence of residual dislocated hips has markedly decreased [2]. However, before the 1970s, CDH prevention was not available and the prevalence of $\mathrm{CDH}$ was more than $3 \%$. Therefore, residual dislocated hips are not rare in elderly people in present-day Japan.

Conservatively treated $\mathrm{CDH}$ might be a major risk factor for low bone mineral density at the hip and osteoporotic hip fracture [3]. In elderly people, and especially in elderly women, minor trauma like falling can cause a fracture at the proximal femur because of skeletal fragility due to osteoporosis. Therefore, elderly patients with residual dislocated hips may suffer a proximal femoral fracture, although few reports have been published.

We found only one case in previous reports that had suffered the combination of proximal femoral fracture and residual dislocated hip. The case was a 20 -year-old active male with a high congenital dislocation of the hip who sustained a displaced subcapital fracture in a traffic accident [4]. He underwent Girdlestone resection arthroplasty [5] and 2 years after surgery, he had almost full range of motion at the hip and was able to resume his preoperative hobbies, including jogging, swimming, and contact sports.

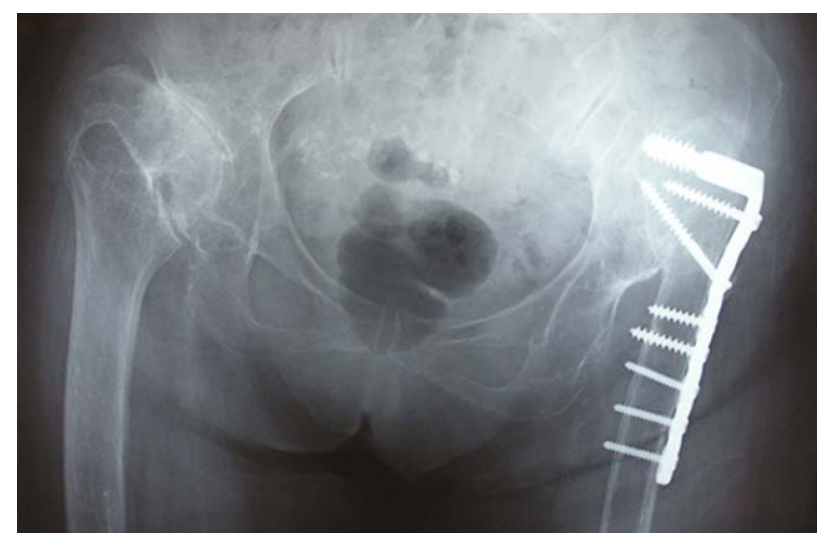

Figure 4. Radiograph 2 years postoperatively. 
The English literature does not cite any reports describing a proximal femoral fracture with residual dislocated hip in an elderly person. Several options are available to treat this combination in an elderly patient, as described below.

\subsection{Total Hip Arthroplasty (THA)}

In patients with a residual dislocated hip undergoing THA, the acetabular component should be placed in the anatomical position and the femur should be shortened to prevent excessive limb lengthening or sciatic nerve injury [6]. In these patients, the original acetabulum is shallow with a short anteroposterior diameter, and this limits the size of the cup and therefore the thickness of the polyethylene insert. Excessive polyethylene wear results in cup revisions. The survival rate in patients with high congenital hip dislocation was reported to be $68 \%$ $78 \%$ at 10 - 20 years [7-12] (Table $\mathbf{1}$ ).

In this case, THA could have been considered because the patient was old and long-term survival was not a major goal. However, we did not choose THA because of the invasiveness of this procedure considering our patient's age and cardiopulmonary status.

\subsection{Open Reduction and Internal Fixation}

Our patient had a long history of a left dislocated hip and had not complained of hip pain before the fracture. Therefore, the most appropriate treatment option to consider would be one that best restores her pre-fracture status, that is, provide a good reduction and a secure internal fixation, disregarding the fact that the hip was dislocated.

In terms of fixation devices, compression hip screws or trochanteric nails are generally used for trochanteric fractures in elderly patients. However, in this case, there were no properly sized lag screws because the femoral head was absent and the femoral neck was short. Nail fixation might be another option, but again in this case, there were no properly sized nails because the proximal femoral shaft was narrow.

We used a 95-degree $\operatorname{DCS}^{\circledR}$ plate because of the availability of the shortest lag screw fitted for proximal fragment and sufficient fixation and strength (ie, $50 \mathrm{~mm}$ ).

\subsection{Arthrodesis}

The ideal patient for hip arthrodesis is a young adult with an active lifestyle. Previous studies have indicated that most young patients who undergo arthrodesis for severe osteoarthritis are very satisfied despite the functional disadvantages of a fusion $[13,14]$. In our case, the patient was old and might incur nonunion and complications associated with prolonged cast immobilization.

\subsection{Proximal Femoral Neck Resection}

Girdlestone resection arthroplasty or femoral head resection has been reported to achieve good pain relief, mobility, and function in older patients with osteoarthritis or ankylosing spondylitis. The Girdlestone procedure for an unreduced fracture-dislocation has been shown to have good results 6 years postoperatively [15]. In our case, we considered resection of the proximal femoral neck fragment as the second choice because of the lack of the femoral head. Our first choice was open reduction and internal fixation to restore the pre-fracture status. If open reduction and internal fixation was technically unfeasible, proximal femoral neck resection might be a better option than THA or arthrodesis in this patient.

\subsection{Conservative Treatment}

Conservative treatment based on traction method and bed rest is one of the options for a proximal femoral fracture in an elderly patient. Compared to conservative treatment, operative treatment with internal fixation devices is more likely to result in the fracture healing without leg shortening, a shorter hospital stay and a statistically non-significant increase in the return of patients back to their original residence [16]. We took conservative treatment of bed rest without traction method at first because the fracture was not displaced. However, the fracture was displaced without bone formation at 3 weeks. Traction method might be more appropriate for conservative treatment.

Table 1. Summary of reported results of total hip arthroplasty in high congenital hip dislocations.

\begin{tabular}{|c|c|c|c|c|}
\hline Reference & No. of hips & $\begin{array}{c}\text { Average age at surgery } \\
\text { (years) }\end{array}$ & Revised rate & $\begin{array}{c}\text { Survival rate } \\
\text { [follow-up period] }\end{array}$ \\
\hline Fredin H [7] & 21 & 46.5 & $43 \%$ & - \\
\hline Numair J [8] & 46 & 41.5 & $17 \%$ & $68 \%$ [15 years] \\
\hline Kerboull M [9] & 118 & 52.0 & $13 \%$ & $78 \%$ [20 years] \\
\hline Hartofilakidis G [10] & 83 & 49.5 & $22 \%$ & $76 \%$ [15 years] \\
\hline Lai KA [11] & 56 & 35.4 & $16 \%$ & 77\% [12 years] \\
\hline Eskelinen A [12] & 68 & 54.0 & $43 \%$ & $73 \%$ [10 years] \\
\hline
\end{tabular}




\section{Conclusions}

Although there are few reports about the combination of proximal femoral fracture and residual dislocated hip in elderly people, more and more patients will suffer this combination because the elderly population continues to increase. To treat proximal femoral fracture of residual dislocated hip in an elderly patient, the patient's overall status, pre-fracture ability, hip joint configuration, and fracture pattern should be considered.

\section{REFERENCES}

[1] J. F. Crowe, V. J. Mani and C. S. Ranawat, “Total Hip Replacement in Congenital Dislocation and Dysplasia of the Hip,” Journal of Bone \& Joint Surgery, Vol. 61, No. 1, 1979, pp. 15-23.

[2] K. Ishida, "Prevention of the Development of the Typical Dislocation of the Hip," Clinical Orthopaedics, Vol. 126, 1977, pp. 167-169.

[3] B. M. Obermayer-Pietsch, D. Walter, S. Kotschan, M. Freigassner-Pritz, R. Windhager and G. Leb, “Congenital hip Dysplasia and Bone Mineral Density of the Hip-A New Risk Factor for Osteoporotic Fracture?” Journal of Bone Minerials Research, Vol. 15, No. 9, 2000, pp. 16781682.

[4] A. M. Taha, "Subcapital Fracture of a Congenitally Dislocated Hip: Revival of Girdlestone Resection Arthroplasty,” Bulletin Hospital Joint Diseases, Vol. 54, No. 1, 1995, pp. 35-42.

[5] G. R. Girdlestone, "Acute Pyogenic Arthritis of the Hip," Lancet, Vol. 1, 1943, pp. 419-421.

[6] D. K. Dunn and W. E. Hess, "Total Hip Reconstruction in Chronically Dislocated Hips,” Journal of Bone \& Joint Surgery, Vol. 58, No. 6, 1976, pp. 838-845.

[7] H. Fredin, L. Sanzén, B. Sigurdsson and L. Unander-Scharin, "Total hip Arthroplasty in High Congenital Dislocation: 21 Hips with a Minimum Five-Year Follow-Up,” Journal of Bone \& Joint Surgery, Vol. 73, No. 3, 1991, 430-433.

[8] J. Numair, A. B. Joshi, J. C. Murphy, M. L. Porter and K. Hardinge, “Total Hip Arthroplasty for Congenital Dysplasia or Dislocation of the Hip: Survivorship Analysis and Long-Term Results,” Journal of Bone \& Joint Surgery, Vol. 79, No. 9, 1997, pp. 1352-1360.

[9] M. Kerboull, M. Hamadouche and L. Kerboull, "Total Hip Arthroplasty for Crowe Type IV Development Hip Dysplasia: a Long-Term Follow-Up Study,” Journal of Arthroplasty, Vol. 16, No. 8 Suppl. 1, 2001, pp. 170-176. doi:10.1054/arth.2001.28368

[10] G. Hartofilakidis and T. Karachalios, "Total Hip Arthroplasty for Congenital Hip Disease,” Journal of Bone\& Joint Surgery, Vol. 86, No. 2, 2004, pp. 242-250.

[11] L. A. Lai, W. J. Shen, L. W. Huang and M. Y. Chen, "Cementless Total Hip Arthroplasty and Limb-Length Equalization in Patients with Unilateral Crowe Type-IV Hip Dislocation,” Journal of Bone \& Joint Surgery, Vol. 87, No. 2, 2005, 339-345. doi:10.2106/JBJS.D.02097

[12] A. Eskelinen, I. Helenius, V. Remes, P. Ylinen, K. Tallroth and T. Paavilainen, "Cementless Total Hip Arthroplasty in Patients with High Congenital Hip Dislocation," Journal of Bone \& Joint Surgery, Vol. 88, No. 1, 2006, pp. 80-91. doi:10.2106/JBJS.E.00037

[13] R. Barmada, E. Abraham and R. D. Ray, "Hip Fusion Utilizing the Cobra Head Plate," Journal of Bone \& Joint Surgery, Vol. 58, No. 4, 1976, pp. 541-544.

[14] G. A. Murrell and R. D. Fitch, "Hip Fusion in Young Adults_-Using a Medial Displacement Osteotomy and Cobra Plate,” Journal of Clinical Orthopaedics, Vol. 300, 1994, pp. 147-154.

[15] R. G. Taylor, "Pseudarthrosis of the Hip Joint," Journal of Bone \& Joint Surgery, Vol. 32, No. 2, 1950, pp. 162165.

[16] H. H. Handoll and M. J. Parker, "Conservative Versus Operative Treatment for Hip Fractures in Adults,” Cochrane Database Systematic Reviews, Vol. 16, No. 3, 2008. 